\title{
An analytical and experimental assessment of flexible road ironwork support structures
}

\author{
Fouad A Mohammad, Andrew C. Collop and Stephen F. Brown \\ Nottingham Centre for Pavement Engineering \\ University of Nottingham \\ University Park \\ NOTTINGHAM NG7 2RD
}

United Kingdom

\begin{abstract}
This paper describes work undertaken to investigate the mechanical performance of road ironwork installations in highways, concentrating on the chamber construction. The principal aim was to provide the background research which would allow improved designs to be developed to reduce the incidence of failures through improvements to the structural continuity between the installation and the surrounding pavement. In doing this, recycled polymeric construction materials (Jig Brix) were studied with a view to including them in future designs and specifications. This paper concentrates on the Finite Element (FE) analysis of traditional (masonry) and flexible road ironwork structures incorporating Jig Brix. The global and local buckling capacity of the Jig Brix elements was investigated and results compared well with laboratory measurements. FE models have also been developed for full-scale traditional (masonry) and flexible installations in a surrounding flexible (asphalt) pavement structure. Predictions of response to wheel loading were compared with full-scale laboratory measurements. Good agreement was achieved with the traditional (masonry) construction but poorer agreement for the flexible construction. Predictions from the FE model indicated that the use of flexible elements significantly reduces the tensile horizontal strain on the surface of the surrounding asphaltic material which is likely to reduce the incidence of surface cracking.
\end{abstract}

Key Words: Road Ironwork, Pavement, Finite element, Buckling, Cracking 


\section{Introduction}

It is estimated that about $£ 210 \mathrm{~m}$ is spent annually in the UK on installation and reinstatement of road ironwork (Brown and Brown, 1997). A normal reinstatement would be planned for the period between the morning and evening rush hours and the bedding and reinstatement materials used must, therefore, be able to withstand traffic loading very soon after installation. Frequently, the work is hurried and not carried out to a high standard, requiring repair after a short period, again with similar material and labour costs. A modest improvement in understanding of the interaction between installations and traffic loading could lead to considerable savings, estimated to be $£ 6 \mathrm{~m}$ per year.

In a previous project undertaken at the University of Nottingham the causes of premature failure in the bedding materials in road ironwork installations were investigated (Brown \& Brown, 1997, 1998, 1999). Results from full-scale laboratory tests, field tests and FE modelling indicated that, under certain loading situations, tensile stresses can be generated in the bedding material which can exceed its tensile strength. This research resulted in improved ironwork designs to minimise these stresses and an improved bedding mortar specification to ensure sufficient tensile strength, compressive strength and shrinkage characteristics of the material (Brown, 2001; Highways Agency, 2002). The improved understanding of the ironwork/bedding material system developed from this project formed the starting point for the research described in this paper.

Although results from the previous project have led the way to improved mortar specifications, the problem of premature cracking in the surrounding asphalt surfacing material was not directly addressed. This material is usually a hot asphalt or a proprietary emulsion product and is generally placed immediately after the ironwork has been installed and the bedding material has hardened. Field observations of inservice road ironwork installations have shown that extensive cracking, initiated from the corners of the installations, can occur in the asphalt without visible deterioration of the bedding material (Brown \& Brown, 1997). The mechanism for this damage is not fully understood, although it seems likely that it is related to the mismatch between the in-situ vertical stiffness of the road ironwork installation and the surrounding pavement structure. Results from in-situ testing have also shown that the 
vertical stiffness directly over the chamber can be a factor of 2.5 greater than the vertical stiffness away from the installation (Brown \& Brown, 1997). This mismatch in stiffness is likely to cause high tensile and shear stresses and strains in the asphalt material adjacent to the installation that may lead to premature cracking and damage.

The research described in this paper forms part of a larger project that involved a study of the overall structural characteristics of road ironwork installations, concentrating on the chamber construction. The principal aim was to provide the background research which would allow improved designs to be developed to reduce the incidence of failures. In doing this, recycled polymeric construction materials were studied with a view to including them in future designs and specifications. They were chosen partly to produce a lower stiffness installation and partly for reasons of sustainability. The breadth of research was similar to, and built on, results from the earlier work and involved field testing, laboratory full-scale testing, materials testing and FE analysis.

This paper describes FE analyses that were undertaken using the ANSYS program to better understand the mechanical performance of road ironwork installations that incorporate flexible elements. The paper is divided into two main sections. In the first section, global and local buckling analyses of the flexible elements are described and compared with experimental results. In the second section, FE models of a traditional masonry chamber construction and a flexible construction are developed and validated with measurements from full-scale laboratory experiments. The validated models are then used to investigate the effect of the flexibility on critical values of deflection and strain.

\section{Flexible Elements}

The material used to introduce flexibility into the chamber wall, known as "Jig Brix", is a polymeric building brick (made from recycled material) designed as a replacement for concrete or masonry. Each brick has an interlocking system that allows sections to be built-up from single bricks without the need to any additional bonding. A photograph of a typical single Jig Brix element is shown in Figure 1. It can be seen from this figure that the shape of the Jig Brix element is complex. The primary material used in its manufacture is recycled polypropylene. 
The main geometrical properties of a single Jig Brix element are summarised in Table 1. The cross-sectional area, moment of inertia, elastic section modulus and radius of gyration were determined using a purpose-written computer program based on a numerical procedure where any geometric shape can be treated as a general polygon (see Cope et al, 1982 for further details).

Young's modulus and Poisson's ratio of the recycled polyproplyene material were estimated from laboratory experiments to be approximately $1,000 \mathrm{MPa}$ and 0.25 respectively. It was found that these values were not strongly dependent on temperature and loading frequency (see Collop et al, 2002 for further details).

\section{Buckling}

The main loading mechanism for an in-service road ironwork installation located in the wheel path of a road is due to traffic loading. As a wheel passes over an installation, the load is transferred into the chamber wall mainly in compression. Since the height of the chamber wall can be quite large, it is necessary to investigate the buckling capacity of the wall to ensure that this mode of failure does not occur. Because of the complex nature of the Jig Brix elements, two types of buckling could occur. These are global buckling as a result of the wall acting as a single unit, and local buckling due to failure in an individual Jig Brix element. Both these failure mechanisms were examined in the following sub-sections. The buckling capacity of columns comprising a number of single width Jig Brix elements stacked vertically was investigated and results compared to laboratory experiments.

\subsection{Global Buckling Analysis}

The global buckling capacity of a Jig Brix column under compressive loading can be determined using the well known Euler buckling formula, (Popov,1999):

$$
P_{c r}=\frac{\pi^{2} E I}{\left(L_{e}\right)^{2}}
$$

where: $P_{c r}=$ Critical buckling load

$E=$ Young's modulus

$I=$ Second moment of area 


$$
L_{e}=\text { Effective length }
$$

The effective length $\left(L_{e}\right)$ depends on the boundary conditions at each end of the column. For comparison with the experimental results, a cantilever column was most appropriate $\left(L_{e}=2 \mathrm{~L}\right)$. Calculations were also undertaken for a column with pinned ends $\left(L_{e}=\mathrm{L}\right)$ because, in reality, where the Jig Brix are part of a chamber construction, the end constraint is likely to be between these two cases.

Figure 2 shows the predicted global buckling capacity plotted as a function of the height of the Jig Brix column. It can be seen from this figure that the global buckling capacity is inversely proportional to the height of the column and the capacity for the pinned end conditions is greater than the capacity for the cantilever end condition. It can also be seen from Figure 2 that the global buckling capacity is between approximately $15 \mathrm{kN}$ and $60 \mathrm{kN}$ for a $600 \mathrm{~mm}$ high Jig Brix column. In practice, the cross section of a Jig Brix wall in a chamber construction typically comprises two units, linked horizontally, providing a double thickness wall which will significantly increase the buckling capacity. For example, assuming that there is no coupling (which is a pessimistic assumption) the global buckling capacity will be doubled to at least $80 \mathrm{kN}$.

\subsection{Local Buckling Analysis}

Local buckling might be expected for part of the Jig Brix units when it is subjected to axial compression because it consists of relatively thin webs, flanges and stiffeners, Figure 1. The local buckling capacity of the Jig Brix unit cannot be accurately determined using an analytical method due to the complex shape of the Jig Brix elements. Therefore, FE analysis was undertaken to determine the local buckling capacity of a Jig Brix column made of one, two or three Jig Brix units stacked vertically.

In the FE analysis, the Jig Brix column was represented using a series of rigidly connected thin plates, discretised using 8-node structural shell elements as shown in Figure 3. A geometrically nonlinear analysis was undertaken for both boundary conditions. 
The numerical results are also shown in Figure 2 and the predicted local buckling failure mode is shown in Figure 4. It can be seen from Figure 2 that, as with the global buckling predictions, the local buckling capacity is greater for the pinned end conditions compared to the cantilever end condition. It can also be seen that results for the local buckling capacity show a lower sensitivity to the height of the Jig Brix column compared to the predicted global buckling capacity. Figure 2 also shows that, for both end conditions, local buckling is predicted to occur before global buckling for column heights below approximately $350 \mathrm{~mm}$.

\subsection{Comparison with Experimental Results}

Laboratory experiments were also undertaken to determine the buckling capacity of a Jig Brix wall 2 elements wide and 1 or 3 elements in height (Collop et al., 2002). Results are shown in Figure 2 and a photograph of a local buckling failure for a 1element high column is shown in Figure 5. For both cases, the mode of failure was local buckling. It can be seen from Figure 2 that the measured local buckling capacity agrees well with the predicted local buckling capacity assuming a cantilever end condition. It can also be seen by comparing Figure 5 with Figure 4 that there is good agreement between the local buckling failure mode shapes obtained from the experiments and predicted by FE analysis.

\subsection{Practical Implications}

The worst case practical scenario in a Jig Brix construction will occur when the wheel load is transferred directly through the frame onto one wall of the installation. Assuming a standard $20 \mathrm{kN}$ wheel load, the factor of safety based on the experimental results will be approximately 3 for a single skin wall, comprising 3 no. Jig Brix, and approximately 6 for a double skin wall, comprising 3 no. Jig Brix. It should also be noted that, in reality, the factor of safety will be greater than these figures since it has been assumed that the wheel load will be transferred through a column of singlewidth Jig Brix.

\section{FE Modelling of Road Ironwork/Pavement Systems}

To investigate the behaviour of road ironwork installations comprising flexible Jig Brix elements, three-dimensional FE analysis was used. Two basic models were 
developed representing flexible and traditional masonry installations. The models were validated using data from full-scale laboratory testing. A schematic of the two laboratory installations is shown in Figure 6. The validated models were then used to investigate the effect of varying the height of the Jig Brix wall in the chamber constructions.

\subsection{FE Models}

To simplify the complex geometry of the Jig Brix elements (see Figure 1), solid 20node brick elements were used with an equivalent Young's modulus of 400MPa. This was determined by equating the relative axial and bending stiffness of a single Jig Brix element to those of an equivalent solid brick element. Mechanical properties for the other materials used in the FE analysis are detailed in Table 2. These values were either obtained from experimental work (Collop et al., 2002 and Brown, 1997) or were taken from available literature (e.g. Ashby and Jones, 1998).

An equivalent static wheel load of $18 \mathrm{kN}$ was assumed to be distributed over a rectangular area of approximately $200 \times 300 \mathrm{~mm}^{2}$ (this was the wheel load used in the laboratory tests). The load was placed along the center line of the chamber creating an axis of symmetry thus simplifying the model and decreasing the computation time. For both chamber constructions, several locations of the load were considered to simulate tracking of the wheel over the road ironwork chamber. At the boundaries of the model it was assumed that motion parallel to the boundary is unrestrained whilst motion perpendicular to the boundary is fully restrained. In reality, friction between the edges of the sides and bottom of the pit and adjacent material will mean that motion parallel to the boundary is not completely un-restrained. The response of the structural systems, in terms of displacements, strains and stresses, were calculated at selected critical points for comparison with experimental results.

Sub-modelling was used to investigate the accuracy of the results in a region of interest and to confirm that they did not strongly depend on the mesh density (number of elements). The procedure for sub-modeling consisted of the following steps:

(i) A model for the entire structure was created and analysed,

(ii) A sub-model with a higher mesh density was created and displacement boundary conditions calculated from the full model were applied, 
(iii) The sub-model was analysed and the results were compared to the full model. If the results did not vary significantly, the mesh density in the full model was considered to be adequate. If not, the full model was refined and the procedure repeated.

\subsection{FE Predictions}

Figure 7 shows the predicted surface deflections, adjacent to the centre of the wheel load for various points relative to the centre of the chamber and for both types of chamber construction. The edge of the ironwork cover is $300 \mathrm{~mm}$ from the centre and the extent of the chamber wall is indicated. It can be seen from this figure that, when the load is located $900 \mathrm{~mm}$ from the centre of the cover, the predicted surface deflections are similar in magnitude indicating that the chamber is sufficiently far away not to significantly influence the results. As the wheel approaches the chamber, the predicted surface deflections for the flexible installation become greater than for the traditional masonry installation due to the increased compliance of the system. The largest difference between the predicted surface deflections occurs when the load is applied directly over the chamber wall.

\subsection{Comparison with Experimental Results}

Full-scale experiments were undertaken on the two chamber constructions using the Road Ironwork Laboratory Test Facility (RILTF) at Nottingham. This facility operates over a $4 \mathrm{~m} \times 2.4 \mathrm{~m} \times 1.9 \mathrm{~m}$ deep pit in which the two chambers were constructed within a three layer pavement. A rolling wheel load was applied to the surface of the construction using two pneumatic actuators for the vertical load and a long stoke pneumatic actuator for horizontal movement. Full details of the experimental facility were described by Brown and Brown (1998) and later modification by Collop et al. (2002).

The measured surface deflections for both chamber installations are also shown in Figure 7. It can be seen from this figure that agreement between the predicted and measured surface deflections for the masonry chamber construction is generally good whereas there is poorer agreement between the predicted and measured surface deflections for the Jig Brix construction. This is particularly evident when the load is applied near to the chamber wall where the measured results are significantly higher 
than the predicted results. This may be attributed to the existence of slight gaps between Jig Brix units as they are not a perfect fit with each other due to slight manufacturing imperfections, giving apparently lower chamber stiffnesses than used in the model. However, when the wheel load passes over the manhole, these gaps will tend to close and more realistic stiffness value would be expected. It should also be noted that a number of other simplifications have been made in the model which may contribute to the discrepancy. For example, it has been assumed that there is no relative motion between the outside edge of the chamber wall and the surrounding material and the complex cellular shape of the jig brix units has been replaced by equivalent solid brick elements.

The tensile strains measured at the base of the asphalt layer at two locations are given in Table 3 together with the predicted strains at the same locations for both chamber constructions. It can be seen from the data in this table that, as with the surface deflections, agreement is better for the traditional masonry chamber. The largest recorded difference between experiment and finite element results was $51 \%$ and that was for the standard Jig Brix chamber.

It should be noted that there has been no attempt to calibrate the FE model to better match the experimental results (particularly in the case of the flexible chamber construction).

\subsection{Surface Cracking}

As noted earlier, one of the objectives of this research was to better understand the mechanism for surface cracking in the asphaltic material that surrounds road ironwork construction. Extensive research into cracking of asphalt has been undertaken and it is generally accepted that initiation of cracking is controlled by the level of horizontal tensile strain that develops under traffic and environmental loading (Pell, 1973). The tensile strains shown in Table 3 for both types of construction are of magnitudes that are likely to initiate fatigue cracking in a reasonably trafficked roads. Such cracks would take time to propagate to the surface (Pell, 1973). The FE model was used to investigate the tensile strain at the surface of the asphalt, immediately surrounding the chamber to see whether surface initiated cracking was likely and whether the more 
flexible chamber construction might reduce this possibility. No measurements of surface strain were made in the laboratory experiments.

It was found that when the load was applied away from the chamber wall, tensile strains were generated at the surface of the asphalt induced by the differential vertical stiffness of the pavement and the chamber. Figure 8 illustrates the concept. Figure 9 shows the horizontal strain calculated at the surface of the asphalt layer plotted as a function of distance from the centre of the chamber where the centre of the load was $750 \mathrm{~mm}$ from the centre of the cover. This was found to be the location where the highest horizontal tensile surface strain was predicted for the masonry chamber construction. It can be seen from this figure that, for this construction, there is a small region adjacent to the chamber where the horizontal tensile strain on the surface of the asphalt is quite high. As expected, due to bending of the asphalt layer, the horizontal surface strain directly under the load is compressive. Figure 9 also shows the corresponding situation for a Jig Brix chamber. It can be seen that the maximum horizontal tensile strain adjacent to the chamber is significantly reduced compared with the traditional chamber (by a factor of approximately 4). This indicates that, under these conditions, surface cracking will be much more likely to occur in masonry construction than in the more flexible Jig Brix construction. The magnitude of tensile strain at the surface for masonry construction is consistent with the initiation of cracking.

\section{Summary and Conclusions}

Three-dimensional FE analysis has been shown to be a suitable numerical tool for modelling road ironwork installations. It gives a relatively realistic representation for the geometrical configuration of the structural system and wheel load distribution. The finite element results are in reasonable agreement with those obtained from experimental work.

The buckling capacity for practical heights of a Jig Brix wall under axial compression is more than $50 \mathrm{kN}$. The concept of using Jig Brix as flexible material in manhole construction was found to reduce the abrupt change in stiffness between the manhole and the surrounding pavement. Therefore, it helps distribute the displacement over a larger area both horizontally and vertically, as well as significantly decreasing the 
tensile strain on the top of asphalt layer near the manhole cover. Hence, the potential for development of cracks and eventual failure of the pavement near the manhole chamber is reduced.

\section{Acknowledgements}

The research described in this paper was funded as part of the DTP LINK Inland Surface Transport Scheme. The Collaborating companies were Saint-Gobain Pipelines plc, Stanton Bonna, Phi Design, and Scott Wilson Pavement Engineering Ltd. The authors are grateful for the support and expertise of Mr B V Brodrick and Dr S E Zoorob in conducting the experimental work.

\section{References}

ASHBY, M F and JONES, D R H, (1998) "Engineering materials”, Pergamon Press.

BROWN, C J, (1997) "The performance of road ironwork installations", PhD Thesis, School of Civil Engineering, University of Nottingham, UK.

BROWN, C J and BROWN S F, (1997) "The performance of road ironwork installations", Proc Inst of Civil Eng, the Municipal Engineer, Vol 121, pp 175185.

BROWN, S F and BROWN, C J, (1998) "Laboratory Facility for Testing Road Ironwork Installations", Transportation Research Record No. 1624. Transportation Research Board, Washington, D.C., pp 237-245.

BROWN, S F and BROWN, C J, (1999) "The structural characteristics of manhole installations in pavements" Proc. Inst. of Civil Engineers Transport, Vol 135, No 4, pp 201-208.

BROWN, S F (2001) "Improving the performance of manhole installations in highways", Highways and Transportation, April, pp 22-24.

COLLOP, A. C, BROWN, S F, ZOOROB, S E, MOHAMMAD, F and BRODRICK, B V (2002) "Mechanical performance of road ironwork/pavement systems", Final Report, to LINK Inland Surface Transport Programme, School of Civil Engineering, University of Nottingham, UK.

COPE, R J, SAWKO, F and TICKELL, R G, (1982) "Computer methods for civil engineers", McGraw-Hill Book Company. 
HIGHWAYS AGENCY, (2002) "Chamber tops and gully tops for road drainage and service: installations and maintenance", Design Manual for Roads and Bridges, Vol. 4, Section 2.

Pell, P S, (1973) "Characterisation of fatigue behaviour", Special Report 140, Highway Research Board, Washington D.C. pp 49-64.

POPOV, E P, (1999) "Engineering mechanics of solids", 2nd ed. Upper Saddle River, NJ : Prentice Hall. 


\section{Tables}

Table 1: Geometrical properties of a Jig Brix unit.

\begin{tabular}{|l|l|}
\hline Item & Value \\
\hline Length $(\mathrm{mm})$ & 153 \\
\hline Width $(\mathrm{mm})$ & 76 \\
\hline Height $(\mathrm{mm})$ & 76 \\
\hline Cross-sectional area $\left(\mathrm{mm}^{2}\right)$ & 3710 \\
\hline Moment of inertia $\left(\mathrm{mm}^{4}\right)$ & $2,278,100$ \\
\hline Elastic section modulus $\left(\mathrm{mm}^{3}\right)$ & 29,970 \\
\hline Radius of gyration $(\mathrm{mm})$ & 24.78 \\
\hline
\end{tabular}

Table 2: Mechanical properties of the materials used in FE models for manhole chambers.

\begin{tabular}{|l|l|c|c|}
\hline No. & Item & $\begin{array}{c}\text { Young's } \\
\text { modulus (MPa) }\end{array}$ & Poisson's ratio \\
\hline 1 & Pavement (Asphalt) & 1000 & 0.4 \\
\hline 2 & Sub-base (crushed rock) & 150 & 0.3 \\
\hline 3 & Sub-grade (silty clay) & 50 & 0.4 \\
\hline 4 & Ironwork (ductile iron) & 165,000 & 0.3 \\
\hline 5 & Mortar & 21,000 & 0.14 \\
\hline 6 & Masonry & 14,000 & 0.2 \\
\hline 7 & Concrete slab & 30,000 & 0.2 \\
\hline 8 & Jig Brix & 400 & 0.25 \\
\hline 9 & Rubber & 175 & 0.2 \\
\hline
\end{tabular}

Table 3: Tensile strain at the bottom of asphalt due to $18 \mathrm{kN}$ wheel load tracking along the centre line of the chamber.

\begin{tabular}{|l|l|l|l|l|}
\hline Chamber & $\begin{array}{l}\text { Strain Gauge* } \\
\text { Location }(\mathrm{mm})\end{array}$ & $\begin{array}{l}\text { Measured Strain } \\
\text { (micro strain) }\end{array}$ & $\begin{array}{l}\text { Computed } \\
\text { Strain } \\
\text { (micro strain) }\end{array}$ & $\begin{array}{l}\text { \% under } \\
\text { prediction }\end{array}$ \\
\hline Masonry & 630 & 160 & 128 & 20 \\
& 830 & 140 & 135 & 4 \\
\hline Jig Brix & 630 & 340 & 166 & 51 \\
& 830 & 290 & 142 & 51 \\
\hline
\end{tabular}

\footnotetext{
* Relative to centre of chamber
} 
Figures

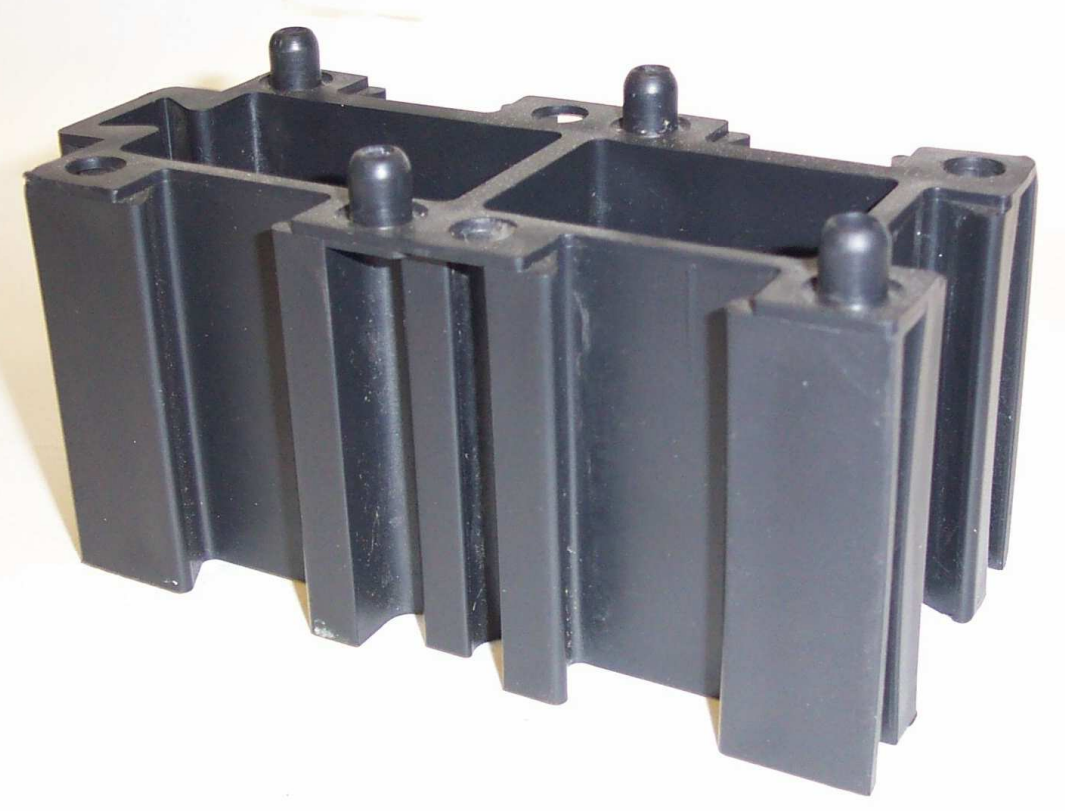

Figure 1: Photograph of a single Jig Brix element.

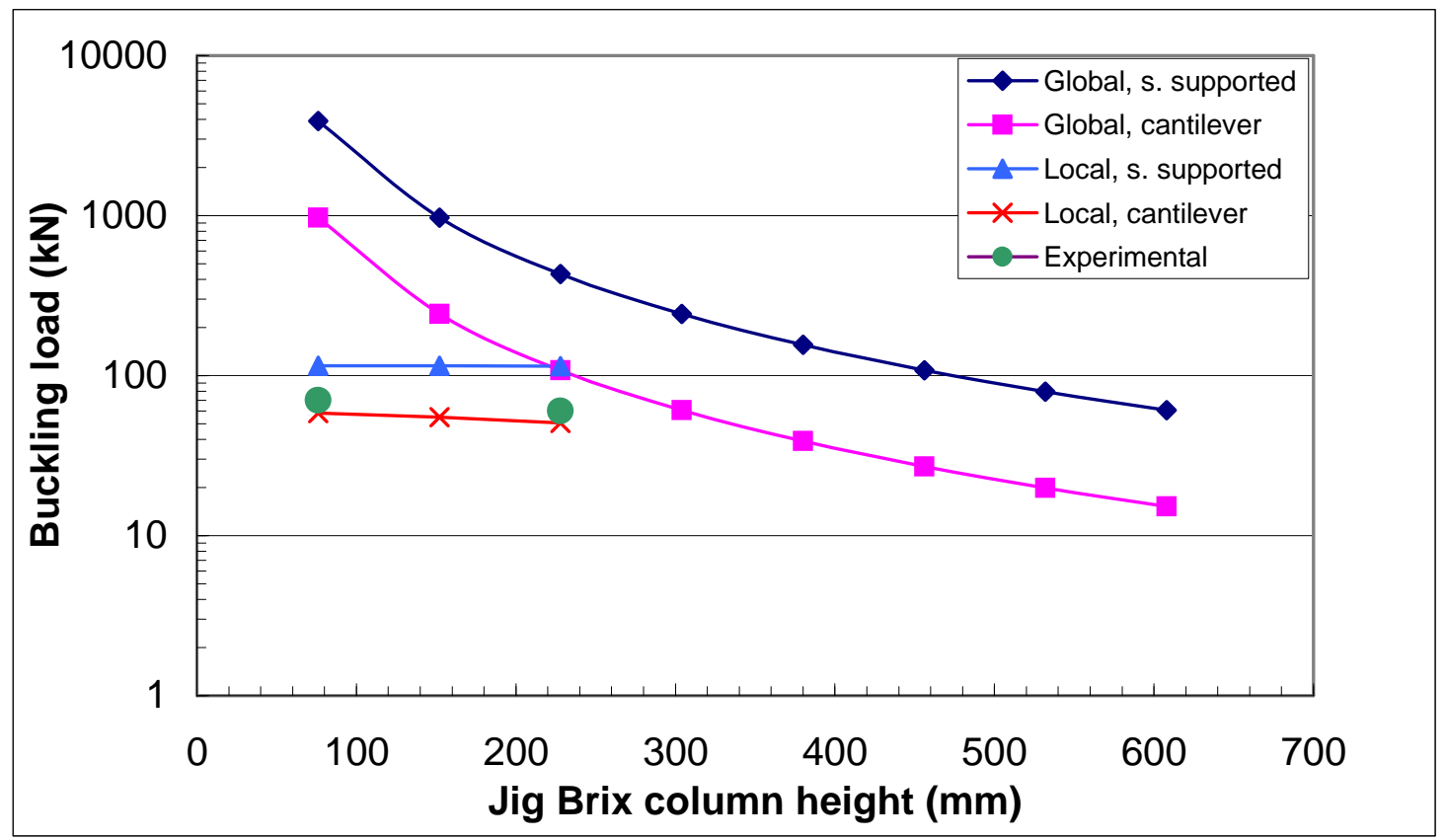

Figure 2: Theoretical and experimental buckling capacity of Jig Brix column. 


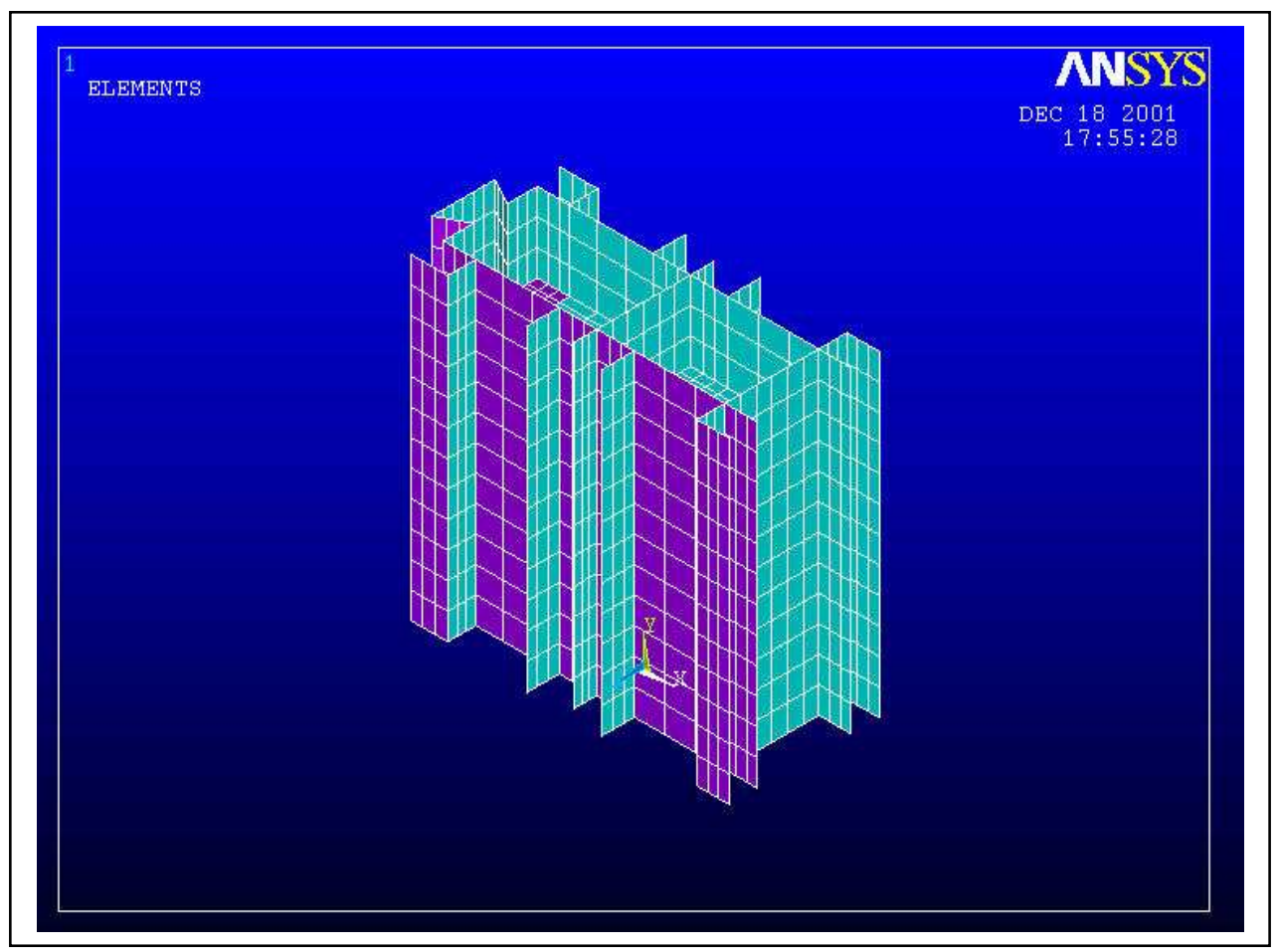

Figure 3: FE mesh of a Jig Brix column using 8-node shell elements.

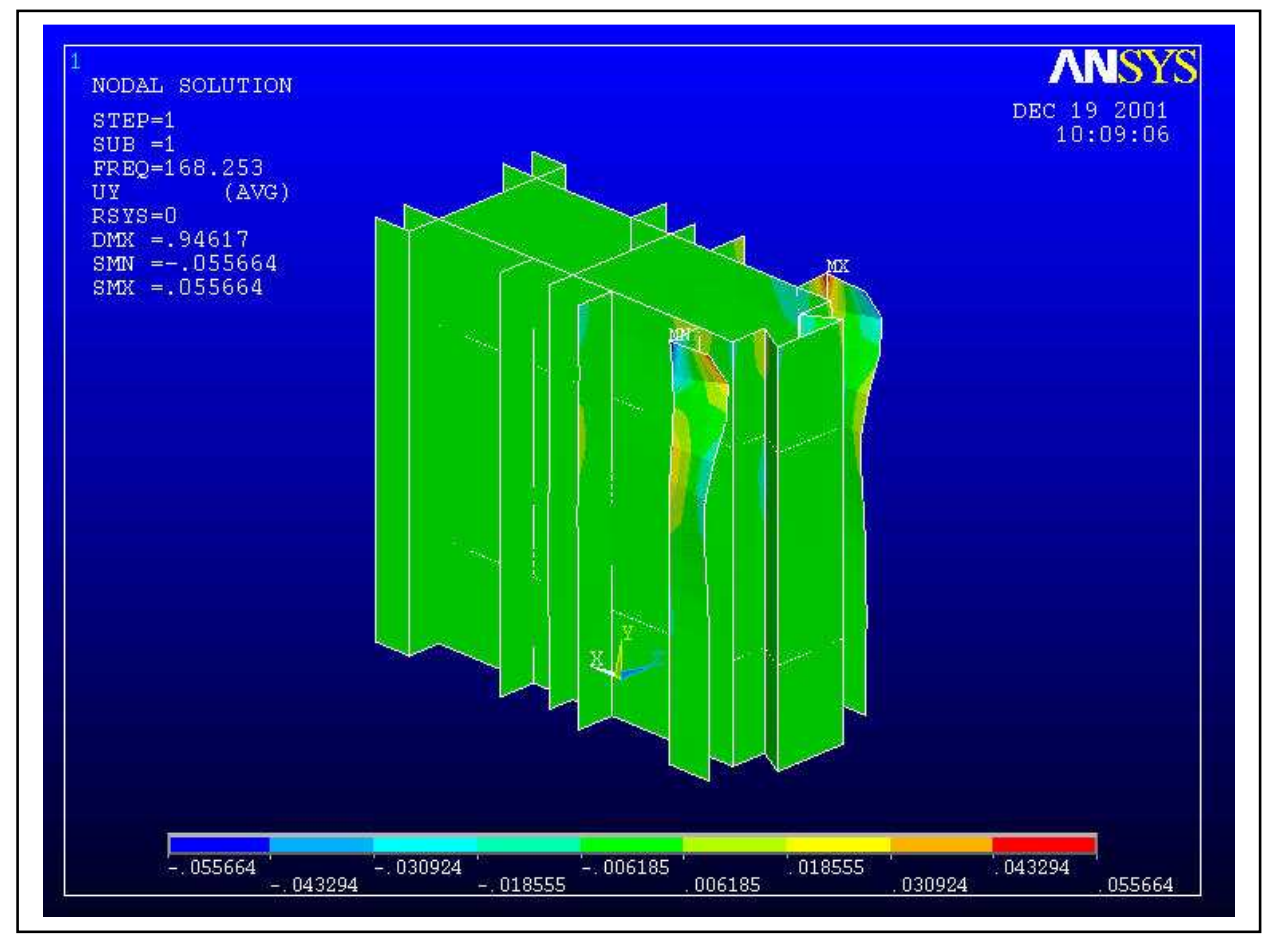

Figure 4: Predicted FE local buckling failure of Jig Brix column. 


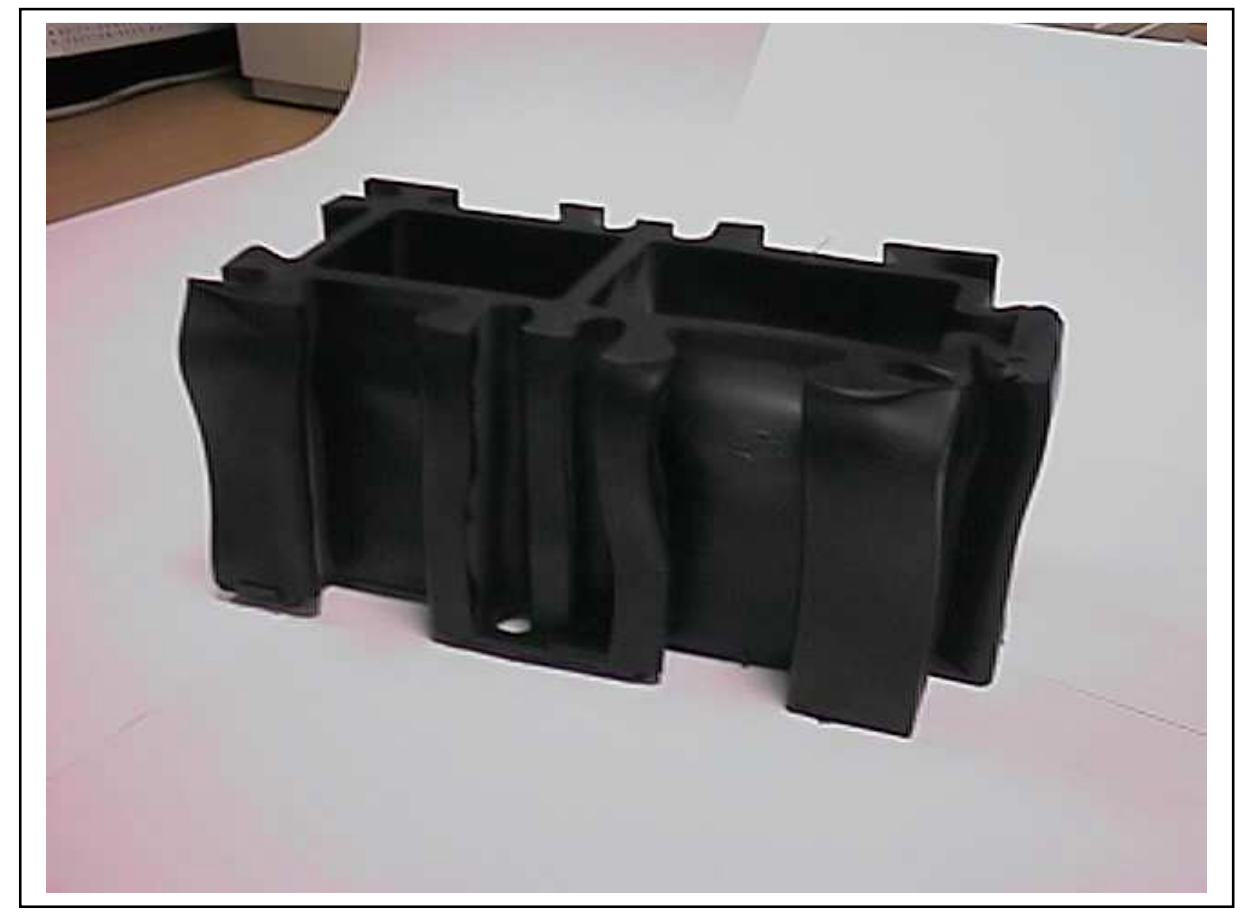

Figure 5: Experimental buckling failure mode of the Jig Brix.

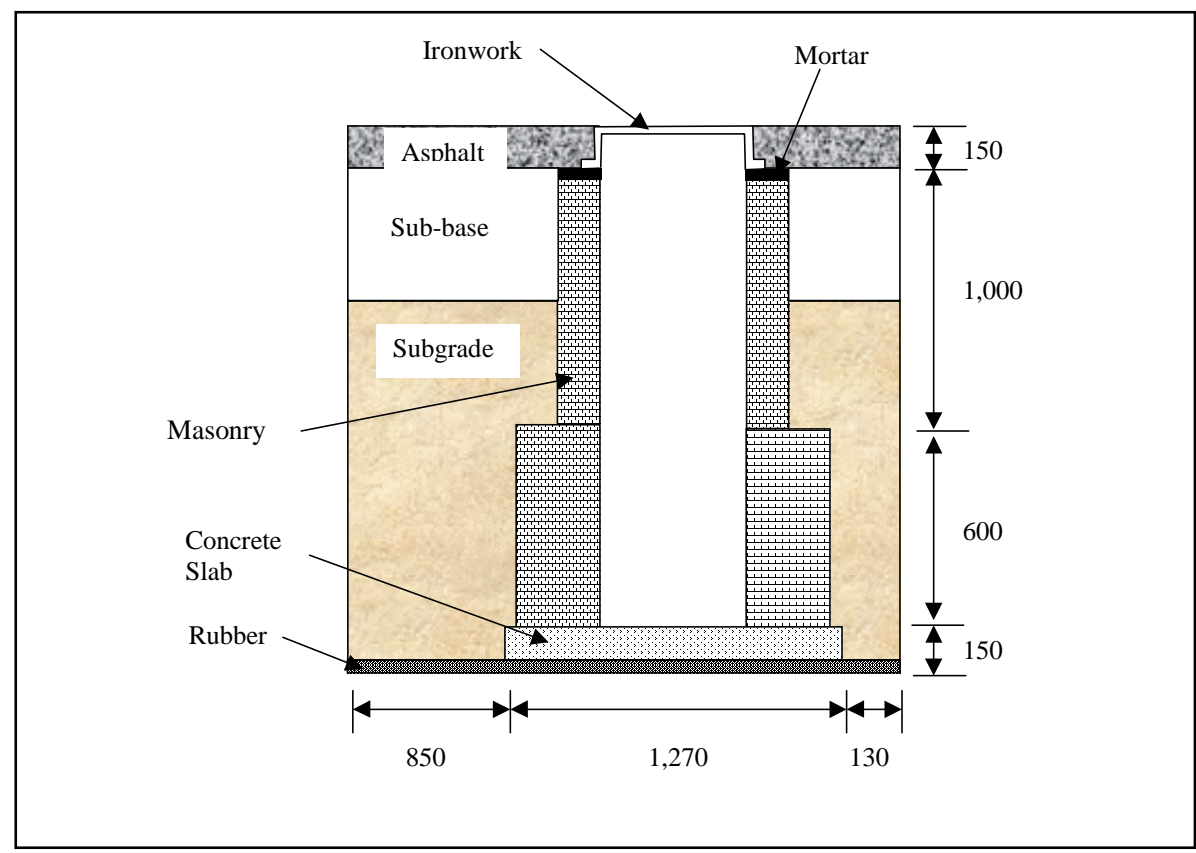

Figure 6(a): Cross-section of the conventional masonry road ironwork installation. (dimensions in $\mathrm{mm}$ ) 


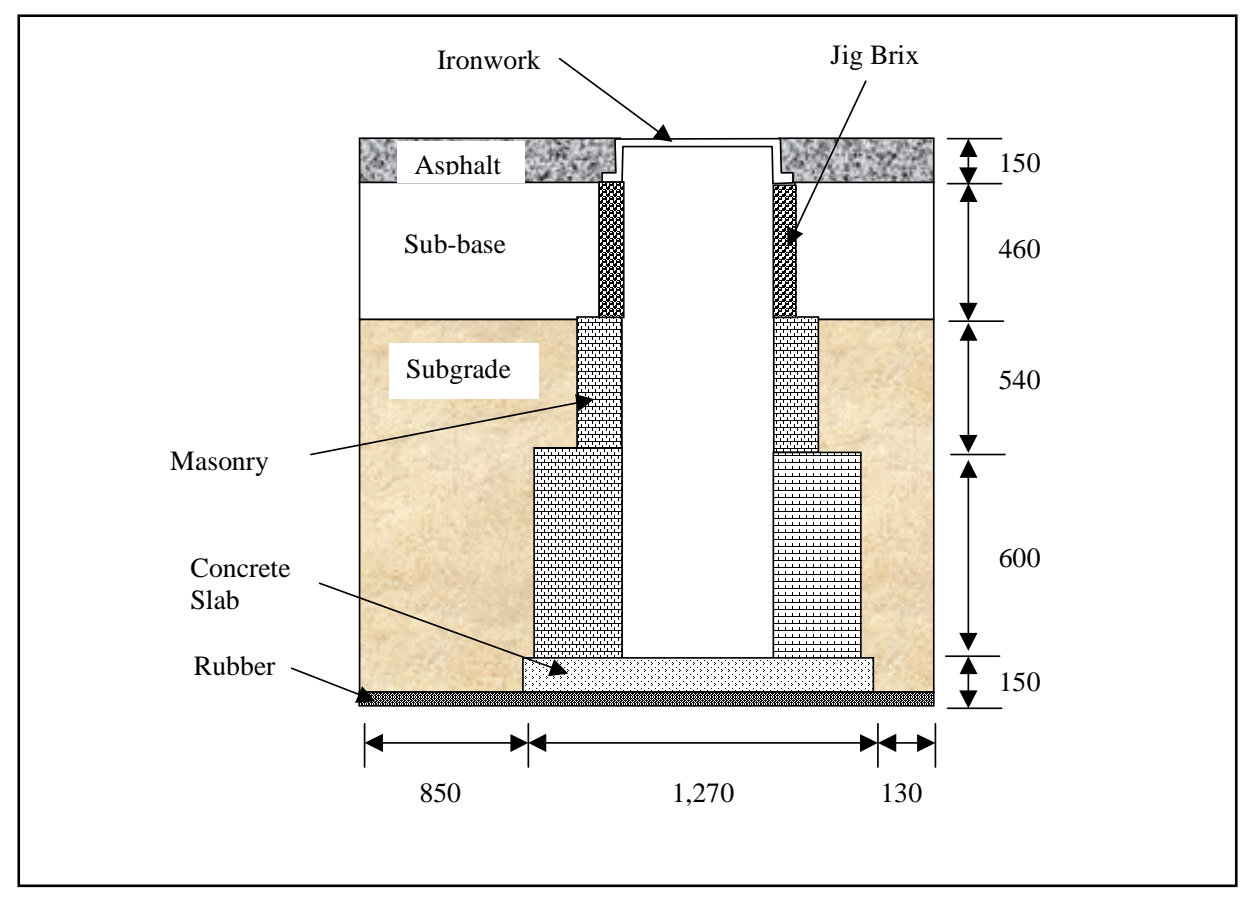

Figure 6(b): Cross-section of the flexible road ironwork installation. (Dimensions in $\mathrm{mm}$ )

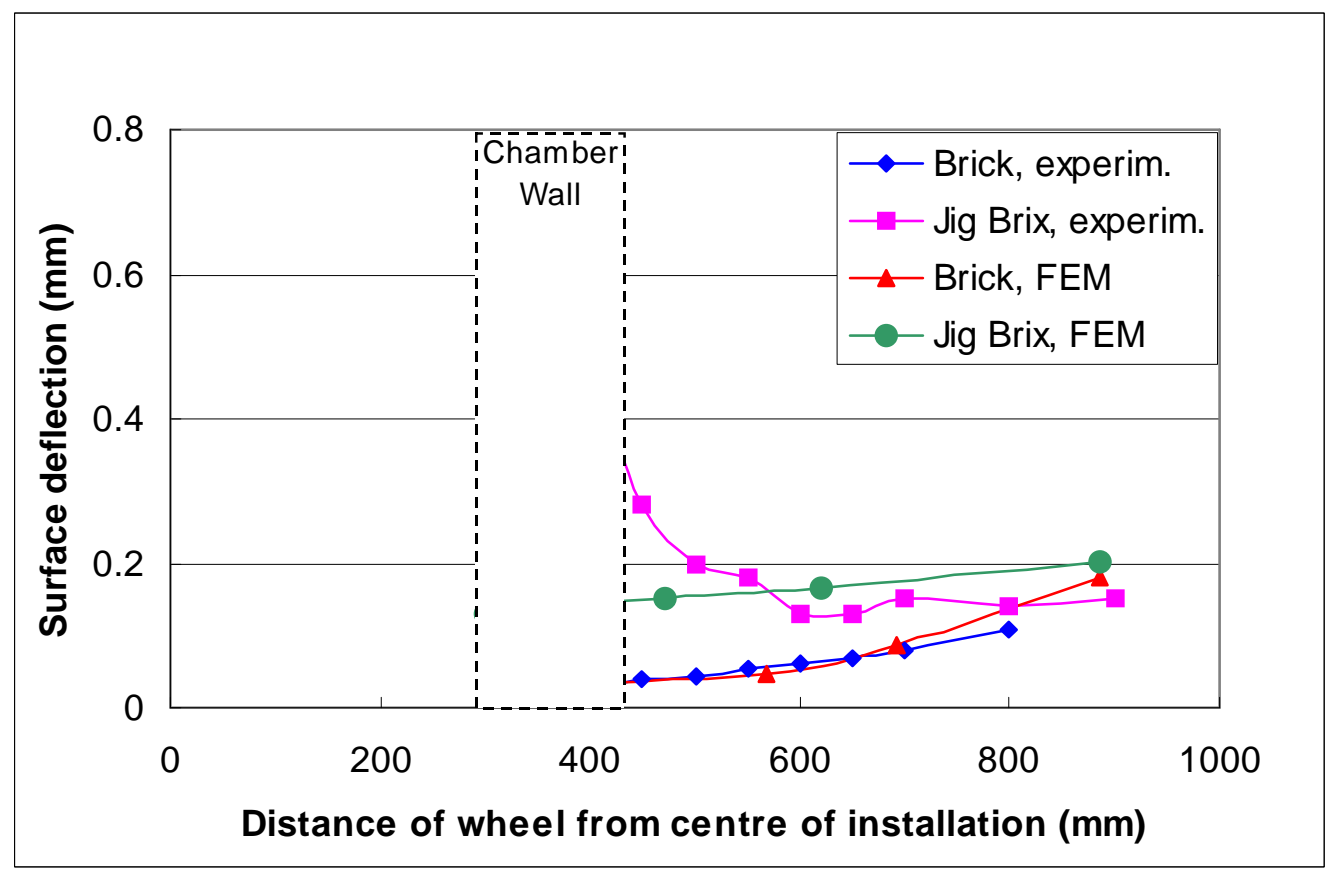

Figure 7: Surface deflections due to wheel load tracking at $18 \mathrm{kN}$. 


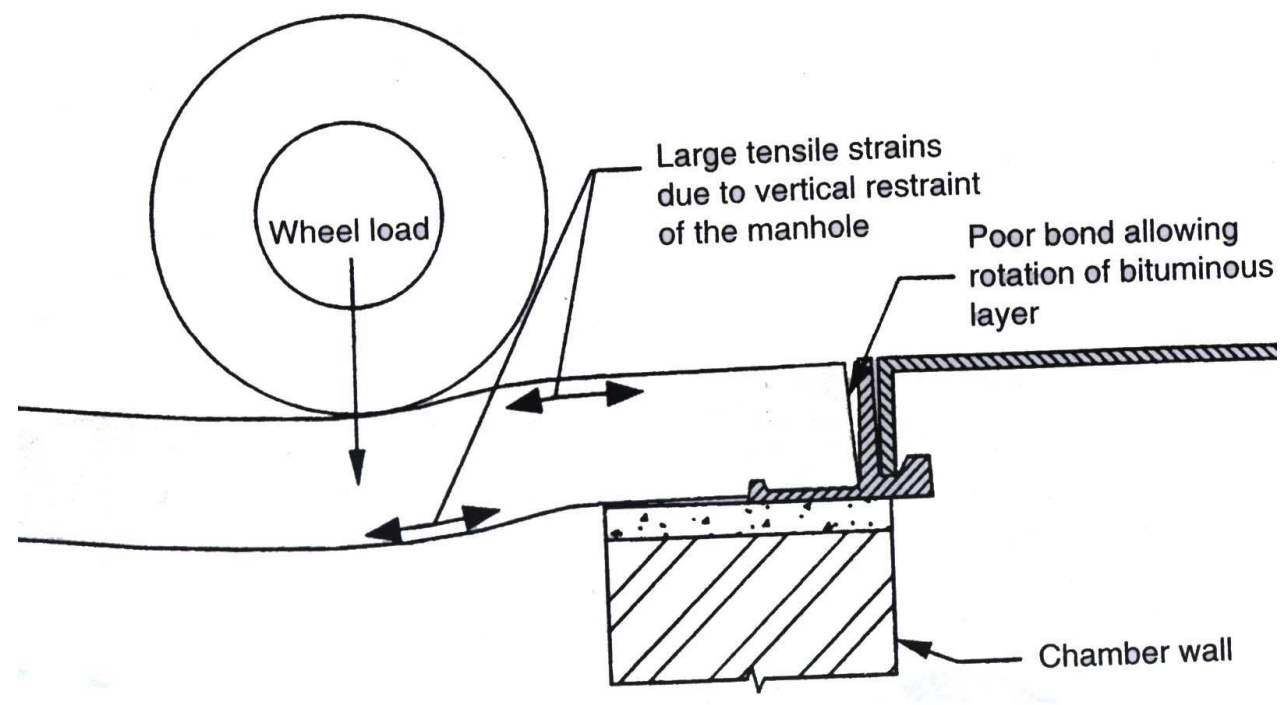

Figure 8: Displaced shape of asphalt layer in the vicinity of a chamber, (after Brown and Brown, 1999).

Figure 9: Finite element prediction of horizontal strain at the top of asphalt layer, positive value means tensile strain. 